\title{
Clinical utility of foam dressings in wound management: a review
}

This article was published in the following Dove Press journal:

Chronic Wound Care Management and Research

17 February 2015

Number of times this article has been viewed

\author{
Jakob Nielsen \\ Karsten Fogh \\ Department of Dermatology, Aarhus \\ University Hospital, Aarhus, Denmark
}

Correspondence: Jakob Nielsen

Department of Dermatology, Aarhus

University Hospital, PP Ørumsgade II,

8000 Aarhus C, Denmark

Tel +457846 I86I

$\mathrm{Fax}+4578461860$

Email jni@ana.au.dk

Background: The management of chronic wounds is a significant medical burden associated with large health care expenditures. Since the establishment of moist wound healing in the 1960s, several types of wound dressings have been developed. However, the evidence for effectiveness when comparing various types of wound dressings is limited.

Objectives: The purpose of this review is 1) to provide a general description of the role of foam in wound therapy and 2) to evaluate the evidence for effectiveness of foam dressings compared to other frequently used products.

Summary and conclusion: Foam has a significant role in the clinical management of chronic wounds and in moist wound healing. There are only a few randomized controlled trials, which in general, show no significant difference in the healing effect of different dressing types. The choice of wound dressing should therefore be based on clinical evaluation of the wound and the periwound skin.

Keywords: foam dressing, chronic wounds, comparative effectiveness, healing, periwound skin, ulcers

\section{Introduction}

Research in wound pathology and healing is complex and extensive. The concepts of moist wound healing were first established in the 1960s, and since then, a number of different wound dressings have been developed. ${ }^{1-3}$ However, studies rigorously examining the optimal choice of wound dressing in randomized controlled trials are limited and data from benchwork (absorption rate, total capacity, vapor transmission, etc) may not always correlate with clinical efficacy. The current clinical use of wound dressings is therefore largely guided by a constellation of consensus agreements, local preferences, and financial considerations. The economic burden of chronic wound management is massive and continues to grow with the expanding aging population in most industrialized countries. The cost of various wound dressings varies greatly. To optimize health care spending, it is important to carefully evaluate the effectiveness of different wound dressings combined with costbenefit analysis. This review is not intended as an exhaustive, systematic review of the literature on current evidence for usage of foam products. Rather, we present an overview of the evidence in the clinical literature, thereby providing a basis for clinicians to make choices in their daily practice of chronic wound management.

\section{Epidemiology and socioeconomic impact of chronic wounds}

The most common chronic wounds are chronic venous leg ulcer, diabetic ulcers, and pressure sores. These wounds result in both substantial loss of quality of life and large 
health care costs. Chronic ulcers are associated with social isolation, reduced psychological well-being, pain, impaired mobility, disturbed sleep, decreased work ability, and limitations in leisure activities. ${ }^{4-6}$

In industrialized countries, the venous leg ulcer is the most frequent chronic wound with an estimated prevalence of $0.1 \%-0.3 \%,{ }^{7,8}$ and a lifetime risk of $1 \% .^{9-12}$ In approximately $25 \%-50 \%$ of patients, the venous leg ulcer persists for over 1 year ${ }^{10,11}$ and two-thirds of these patients will have a reoccurrence within a 5-year period. ${ }^{8}$ Chronic wounds are estimated to have a prevalence of $1 \%$ in the general population and up to $3 \%-5 \%$ in the senior population aged 65 years and older. ${ }^{13}$ The duration of the wounds may span from weeks to several years, while some chronic wounds may never heal. ${ }^{14-17}$

Estimates of the yearly cost of health care services and products for patients with chronic wounds range from approximately $€ 1,300$ to 2,600 (Sweden, 2006 expenditure estimates). ${ }^{18}$ Including indirect and intangible costs to the individual and society, the current estimated cost-of-illness is approximately $€ 9,000$ per year per patient in Germany. ${ }^{19}$

\section{Wound healing and the biological role of exudate}

Wound healing is a complex process resulting in repair of a skin defect by re-epithelialization and scar formation. Wound healing is traditionally divided into three overlapping stages: inflammation, granulation, and maturation. ${ }^{20}$ In the initial inflammation stage, the immune system is activated by release of cytokines, and inflammatory cells are recruited to the wound site. The inflammation causes increased capillary permeability and accumulation of exudate fluid in the wound bed. ${ }^{21}$ In addition to cytokines, the exudate contains plasma components, growth factors, proteases, and protease inhibitors. In the inflammatory stage, the role of the exudate is to promote tissue debridement and clearing of infection, which in turn, prepares the wound bed for re-epithelialization by formation of provisional matrix. ${ }^{22}$ In the granulation and maturation stages, the degree of inflammation and exudate formation decreases, which allows the healing process to progress.

In chronic wounds, the inflammatory stage is commonly maintained due to an underlying pathology (eg, venous insufficiency, diabetes, or autoimmune disease) or complicating factors such as a secondary infection or formation of biofilms. Comparative proteomic analysis of wound exudate from venous leg ulcers show that nonhealing wounds express proteins involved in inflammation and tissue destruction while healing venous leg ulcers are characterized by expression of proteins involved in tissue formation. ${ }^{23}$ Moreover, exudate from chronic wounds also decrease proliferation of keratinocytes, fibroblasts, and endothelial cells, ${ }^{24-28}$ while exudate from active wounds stimulate proliferation. ${ }^{29}$ These findings suggest that optimal management of the exudate plays an important role in stimulating the progression from the inflammatory stage to the granulation stage of chronic wounds.

\section{General considerations for chronic wound management}

Treating chronic wounds is dependent on proper identification and treatment of underlying causes including, complicating metabolic factors and optimizing the local wound environment.

\section{Underlying conditions in patients with nonhealing ulcers}

Patients with venous and arterial insufficiency must have appropriate diagnostic testing performed (ie, sonography including duplex scans and arteriography, respectively) and, if indicated, relevant venous and revascularization surgical interventions. Patients with diabetic foot ulcers typically require multidisciplinary care including optimal diabetes regulation, wound therapy, and adapted footwear. Healing of pressure ulcers requires meticulous care focused on shifting the bodyweight to relieve pressure from the ulcer (and other skin areas at risk) combined with wound care. Patients with suspected immunological ulcers (eg, vasculitis and pyoderma gangrenosum) or unusual wounds require vigorous investigation at specialized centers to determine the underlying cause. These patients often require systemic immunosuppressive therapy and close clinical follow up. In addition to treating the underlying disease, it is essential to correct complicating metabolic factors such as anemia, malnutrition, vitamin and mineral deficiencies, infection, and poorly regulated blood glucose levels.

\section{Edema}

Chronic wounds are associated with edema formation either as a primary event (as seen in venous leg ulcers) or secondary to the inflammatory process. The edema may be localized to the wound and periwound area or extend well beyond the wound. The edema inhibits healing and increases the risk of eczema and secondary infection. Treating the edema is typically achieved by the application of circular compression bandages or use of individually fitted compression stockings. More complicated states of edema may benefit from sustained or intermittent pneumatic compression. 


\section{Local wound management}

Optimal wound healing is based on the principal of a moist wound environment (with the exception of dry gangrene) requiring optimal control of autolysis and debridement, exudate, infection and periwound skin, and edema. Dry and crusted wounds can be hydrated using gels and occlusive dressings retaining moisture. During the inflammatory stages the exudate production can be very high, necessitating the use of wound dressing with high absorptive capacity and frequent change of the wound dressing. In the granulating and maturation stages, the choice of dressing and absorptive capacity is adjusted to match the normally reduced exudate production rate allowing the wound bed to stay sufficiently hydrated. To address the common issues of infection, pain, and odor, various types of wound dressing containing silver, ibuprofen, and charcoal have been developed - all of which are commonly used.

\section{Complications to wound management}

Several complications can arise when wound management is not optimal. A mismatch or imbalance between the absorptive capacity of the foam and exudate formation may lead to drying of the wound bed. This can then lead to adherence of the foam to the wound bed, resulting in pain and trauma upon removal of the dressing.

Conversely, a relative overproduction of exudate may cause leakage of wound exudate leading to unnecessarily frequent dressing changes, as well as trauma, irritation and eczema in the surrounding skin, infection, and foul odor. Infection or colonization with bacteria may also result in release of toxins causing irritations to the skin and wound bed. Contact allergy to modern wound dressings is very rare with the exception of hydrocolloids $(\sim 10 \%-17 \%)$ and silver containing dressings $(\sim 5 \%) \cdot{ }^{30}$ Only a few cases of contact allergy to polyurethane foam have been reported. In these cases contact allergy to chemicals used in the production of polyurethane foam were identified (eg, diphenylmethane diisocyanate, toluene diisocyanate, diaminodiphenylmethane). ${ }^{31-33}$ However, contact allergy to ingredients in other topical wound care products (eg, Balsam of Peru, lanolin, fragrance, triclocarban, and colophony) are frequent and have been reported in up to $57 \%-78 \%$ of patients. ${ }^{34,35}$ Contact allergy should therefore always be considered as a possible complication if the patient develops persistent dermatitis.

\section{Types of wound dressing}

Various wound dressing products are available. These can be categorized based on composition and absorptive capacity and specialized functionality. The most common types include petrolatum impregnated gauze and knit viscose with very low absorptive capacity. Polyurethane foam, silicone, hydrocolloid, hydrofiber, alginate, and advanced combination products are generally of high absorptive capacity. Available on the market are also hydrocellular and hydropolymer foams, which contain polyurethane combined with a wound contact layer of an apertured three-dimensional plastic net, and hydropolymer, respectively. Advanced products containing growth factors and bioengineered epidermal and dermal components are also available on the market. However, these advanced products still lack good evidence for effect and are expensive. They are therefore not commonly used in the general care of chronic wounds. Finally, the so-called "negative pressure wound therapy" (NPWT), is a wound management technique where negative pressure is applied to the wound bed through an occluded polyurethane foam or gauze. NPWT is an active approach to exudate handling and wound closure. NPWT is common and well established in surgical wounds, while its role in the treatment of the various chronic wounds is less established. ${ }^{36,37}$ The use of advanced foam products and NPWT is beyond the scope of this review and will therefore not be addressed further.

\section{Foam types and indications for use}

During the past 30 years, polyurethane foam has become one of the most commonly used wound dressings for exudate management in moist wound healing. Foam consists of a porous structure that is able to absorb fluids into air-filled spaces by capillary action (for detailed information on specific products, visit the respective company websites). The most commonly used foam is polyurethane. Silicone foam is less frequently used as the primary absorbent in wound dressing, but it is often applied as an adhesive wound contact layer. Foam dressings are produced with variable thickness and may be adhesive or nonadhesive. The foams are commonly supplied with a film-backing, which has the purpose of providing a water and microbial resistant barrier to the environment. The film-backings have variable permeability, affecting the capacity of water evaporation and gas exchange. Other types of wound dressings, eg, hydroactive polymers and colloids, are also commonly used in wound therapy. These non-foam materials absorb fluids by expansion, during the binding of fluids into the polymer or colloid, resulting in a gel like substance.

The wound contact layer of the foam products is particularly important because it, both, facilitates transport of the exudate into the foam, and comes in contact with the 
periwound skin. Adhesion to the surrounding skin helps to keep the dressing in place and prevent exudate from traveling along the skin thereby preventing skin irritation and leakage. However, adhesion to the skin may cause irritation, especially if the skin is fragile or if the wound dressing requires frequent changing.

Self-adhesive polyurethane foam and silicone adhesive have been shown to be the least traumatic to the stratum corneum, while acrylic adhesive (used in composite hydrocolloid and polyurethane foam) is more traumatic. ${ }^{38}$

In general, foam closely complies with the so-called Tuner criteria $^{39}$ for ideal wound dressing which includes 1) the ability to maintain moisture at the wound bed; 2) being easy to remove and being able to protect the skin around the wound; 3) protecting against bacteria and other infectious agents; 4) maintaining temperature; 5) providing mechanical protection, cushioning, and conform to body shape; 6) being nontoxic and nonallergenic; 7) being easy to use; and 8 ) being economical and having a long shelf life.

Foams are used in the management of both acute and chronic wounds of both partial and full thickness, and with medium to heavy exudate. Foams may be used as a primary dressing or secondary dressing in combination with amorphous gels applied to the wound bed to provide moisture. The hydrogels are not absorbed into the foam due to their high viscosity. As mentioned previously, foams are also used in NPWT and are commonly used in combination with compression bandaging.

It should be noted that, in general, certain antiseptics may damage the foam product. It is therefore advisable to consult the product information before use of antiseptics (eg, iodine, chlorhexidine, hypochlorite, ether, hydrogen peroxide, oxygenated water, and sodium hypochlorite).

\section{Foam and absorption rate}

The absorption of the wound exudate is a key function of foam dressings. Ideally, the absorption rate and capacity of the foam dressing should balance with the exudate production of the wound. As described above, exudate formation varies depending on the wound type and stage of healing. The optimal dressing must therefore be chosen based on the rate of exudate formation in the individual wound in order to avoid drying-out or maceration of the periwound skin. Product information regarding the absorption rate, evaporation rate, and total capacity of the individual dressings would therefore appear to be clinically useful. ${ }^{40,41}$

However, individual factors, such as the overlaying compression bandage and the relative size of the wound compared to the foam may also markedly affect the performance of the foam. On the one hand, compression may decrease the absorptive capacity due to compression of the air-filled space in the foam. On the other hand, compression may increase the absorption rate due to better wound bed contact. Variable ratios of foam surface area relative to the wound surface area will also affect the effective evaporation. Thus, the choice of which foam will most ideally match the wound is complex and depends on the underlying basic characteristics of the patient's wound. The ability of a given foam to maintain the optimal level of moisture in the wound bed should be evaluated continuously to avoid complications from a mismatch of absorptive capacity to exudate production.

\section{Results from clinical trials}

Given the heavy health care cost involved in the treatment of chronic wounds, there is an increasing interest in investigating the efficacy of various wound dressings to identify products that most efficiently result in wound healing. However, many of the investigations conducted over the past 25 years have limitations in study design, which raise general concerns about bias, limited generalizability, and external validity, and thus the significance of the results. This may in part be due to difficulties in carrying out blinded investigations in this patient group and due to the variability in etiology and presentation of chronic wounds. In the following section, results from selected randomized controlled studies will be briefly discussed.

\section{Venous leg ulcers}

The effect of foam dressing compared to other types of wound dressing in patients with chronic venous leg ulcers has recently been examined. ${ }^{42}$ In this systematic review of the literature, 12 randomized controlled studies were deemed of sufficient design quality to be included in the review. The overall conclusion was that there was no significant difference in the effect on healing time, proportion of ulcers healed at 12 and 16 weeks, or healing rates, when comparing polyurethane foam with hydrocellular polyurethane foam, ${ }^{43-45}$ hydrocapillary dressings, ${ }^{46}$ hydrocolloid, ${ }^{47-51}$ paraffin gauze, ${ }^{52,53}$ and knit viscose ${ }^{54}$ Although there were no significant differences in the primary outcomes of wound healing, there appeared to be a significantly better exudate handling by polyurethane foam over hydrocellular foam, resulting in less problems with leakage, less frequent changes of the wound dressing, and lower material cost $(n=60) .{ }^{44}$ Similar results and limitations regarding exudate handling were also reported in one study comparing hydrocolloid with foam. ${ }^{49}$ In addition, hydrocolloid was also evaluated as more troublesome to remove and thus, more 
time consuming compared to polyurethane foam in two of the studies. ${ }^{48,50}$ Pain and adhesion of the dressing to the wound bed was reported more frequently when using paraffin gauze compared to polyurethane foam $(n=61){ }^{52}$

\section{Diabetic foot ulcers}

The diabetic foot ulcer is the result of diabetic neuropathy and may be complicated with peripheral arterial disease. Diabetic foot ulcers affect approximately $15 \%$ of all patients with diabetes at some point during the course of their disease $\mathrm{e}^{55,56}$ and affects approximately $1 \%-4 \%$ of diabetics at any given time. ${ }^{57,58}$ For diabetic ulcers, the data supporting choice of optimal wound dressing is very limited ${ }^{59}$ and there is no evidence of a more favorable outcome when using foam products compared with gauze dressing ${ }^{60-62}$ and/or hydrocolloid. ${ }^{63}$ In one study from 1993, polyurethane foam was shown to be superior to alginate wound dressing after 12 weeks of follow up, ${ }^{64}$ while the same effect was not observed in another study from 1994 with 8 weeks of follow up. ${ }^{65}$

\section{Pressure ulcers}

Pressure ulcers are ischemic wounds affecting the skin and underlying tissue. Prolonged pressure against skin by underlying bone or cartilage causes reduced tissue perfusion resulting in necrosis and wound formation. The primary intervention is prevention by alleviating pressure from the threatened tissue area. However, once a wound has been formed, basic wound care is necessary - in addition to alleviating pressure to the area and optimization of the nutritional state. ${ }^{66}$ With respect to pressure ulcers, there is only limited evidence to support advantages of foam over other wound dressings. One randomized controlled study has shown that foam improved healing compared to simple gauze when used for treatment of superficial pressure ulcers characterized by blisters and abrasions and only partial loss in skin thickness. ${ }^{67}$ Similarly there is evidence that hydrocolloids may be favorable when compared to simple gauze dressing. ${ }^{68-70}$ However, there is no evidence indicating whether foam is better than hydrocolloid. ${ }^{71}$ A clinical trial is currently being undertaken to address this question. $^{72}$

\section{Fungating wounds}

Fungating wounds arise from late stage cancer. This type of wound is characterized by heavy exudate, malodor, infection, hemorrhage, and pain. The patients usually have a short life expectancy and the wounds inflict severe psychological distress. ${ }^{73-77}$ No studies, to our knowledge, have investigated the effectiveness of foam compared to other wound dressings, with specific regard to fungating wounds. In clinical "best practice", and without supporting evidence, it is important to choose wound dressings with sufficient absorptive capacity, ie, alginates, to avoid leakage. In addition, it may be favorable to use silver containing products which may help reduce odor. ${ }^{78}$

\section{Clinical evidence for the use of combination products}

Bacterial colonization and infection are important factors that may complicate wound healing, particularly in chronic wounds. Furthermore, widespread use of systemic and topical antibiotics has led to resistant bacterial strains such as methicillin-resistant Staphylococcus aureus (MRSA) which is a noteworthy health issue worldwide. The so-called "best practice" for controlling the microbial burden in wounds is not defined. Clinically infected wounds are commonly treated with systemic antibiotics and there is no evidence for other recommendations. ${ }^{42}$ Colonization of wounds presents a double problem; by both potentially causing delayed healing and by representing a potential source for cross-contamination. The use of dressings, notably those containing certain antiseptic agents, can be a valuable option to controlling infection while promoting wound healing. ${ }^{79}$

\section{Dressings containing silver}

Dressings containing silver are often used to control the polymicrobial wound bioburden, although its efficacy against aerobic, anaerobic, and antibiotic-resistant microorganisms is not well established. The use of silver-containing dressings in burn patients has been evaluated in a review, and it was concluded that that silver-containing dressings and topical silver were either "no better" or "worse" than control dressings in preventing wound infection and promoting healing of burn wound.$^{80}$ Moreover, systematic Cochrane reviews have not found evidence for the use of silver containing wound dressings (not only foam based but various kinds of wound dressings) in the treatment of infected or contaminated chronic wounds. ${ }^{42}$ Despite this lack of strong evidence, many wound care clinics commonly use silver-containing dressings to treat chronically contaminated/colonized wounds.

\section{Ibuprofen-releasing dressing}

To combat the common issue of pain in wounds a polyurethane foam product releasing ibuprofen into the wound bed was developed, showing pain reduction and no systemic absorption of ibuprofen. ${ }^{81}$ Ibuprofen is evenly distributed throughout the dressing and is released when exposed to 
the moist environment at the surface of exuding wounds. ${ }^{82}$ Ibuprofen-releasing foam was also shown to reduce pain at the donor site in skin graft patients. ${ }^{83,84} \mathrm{~A}$ significant pain reduction has also been demonstrated using ibuprofenreleasing polyurethane foam in patients with painful chronic wounds. ${ }^{85-87}$ Moreover, the quality of the pain reduction was investigated and described as clinically relevant and the capacity to handle the exudate was not affected. ${ }^{88,89}$ Lastly, ibuprofen-releasing polyurethane foam was studied in combination with a silver-releasing contact layer in an open study which showed evidence of reduced wound pain and promotion of healing without compromising safety. ${ }^{90}$

\section{Limitations of the current literature and future goals}

Currently there is no solid evidence suggesting clear superiority of any of the commonly used products. The primary outcomes in many studies are typically absolute healing time, proportion healed, or wound size reduction after a given time period of observation. These results may be subject to bias as the participants who did not heal may be censored in the statistical analysis. A time-to-event analysis (ie, time to complete healing or other defined outcome) with adjustment for covariates, such as the baseline wound size, may offer a more rigorous statistical model.

Another common source of bias is due to inadequate methods of randomization and allocation to treatment, no blinding of patient, personnel and outcome assessment, incomplete data, observer and measurement bias, and finally selective reporting. Future studies should follow the CONSORT (Consolidated Standards of Reporting Trials) guidelines to improve the quality of the randomized controlled trials. ${ }^{91}$ Studies must also clearly report on the wound care regime and concurrent treatments such as compression. Secondary outcomes such as pain and disease-related quality of life should be reported using validated methods and all data should be presented. Lastly, the inclusion and exclusion criteria should be carefully considered such that the results can be generalized. To date, many studies have excluded patients with clinical infection, which is very common in this patient population, and thus limits the clinical applicability of the study result. Carefully designed studies are needed to investigate which wound care product can provide the most optimal balance between cost and effectiveness.

\section{Conclusion}

Foam dressings are widely used in the daily management of both acute and chronic wounds of differing etiologies.
In general, the evidence supporting the use of foam products over other wound dressings is limited. In clinical practice, foam dressings are easy to use and fulfill most of the ideal criteria for a dressing used in moist wound healing. Ibuprofen-releasing and silver-containing combination foam products may be appropriate to reduce pain and bioburden, respectively. Given the general lack of solid evidence, wound care professionals ought to choose dressings based on clinical evaluation of the wound and the periwound skin.

Further research should be design based on the CONSORT guidelines and aim to address the efficacy and cost effectiveness of different wound dressings to allow for evidence-based decision-making on the best wound care products.

\section{Disclosure}

The authors report no conflicts of interest in this work. No external funding sources supported this review. Dr Nielsen and Dr Fogh are salaried employees of Arhus University and/ or Aarhus University Hospital.

\section{References}

1. Hinman CD, Maibach H. Effect of air exposure and occlusion on experimental human skin wounds. Nature. 1963;200:377-378.

2. Winter GD. Effect of air exposure and occlusion on experimental human skin wounds. Nature. 1963;200:378-379.

3. Jonkman MF, Hoeksma EA, Nieuwenhuis P. Accelerated epithelization under a highly vapor-permeable wound dressing is associated with increased precipitation of fibrin(ogen) and fibronectin. $J$ Invest Dermatol. 1990;94(4):477-484.

4. Harding K, Cutting K, Price P. The cost-effectiveness of wound management protocols of care. Br J Nurs. 2000;9(Suppl 19):S6, S8, S10 passim.

5. Herber OR, Schnepp W, Rieger MA. A systematic review on the impact of leg ulceration on patients' quality of life. Health Qual Life Outcomes. 2007;5:44. doi: 1477-7525-5-44.

6. Persoon A, Heinen MM, van der Vleuten CJ, de Rooij MJ, van de Kerkhof PC, van Achterberg T. Leg ulcers: a review of their impact on daily life. J Clin Nurs. 2004;13(3):341-354.

7. Nelson EA. Venous leg ulcers. Clin Evid (Online). 2011;2011:1902.

8. Callam MJ, Ruckley CV, Harper DR, Dale JJ. Chronic ulceration of the leg: extent of the problem and provision of care. $\mathrm{Br} \mathrm{Med} \mathrm{J} \mathrm{(Clin}$ Res Ed). 1985;290(6485):1855-1856.

9. Baker SR, Stacey MC, Singh G, Hoskin SE, Thompson PJ. Aetiology of chronic leg ulcers. Eur J Vasc Surg. 1992;6(3):245-251.

10. Lees TA, Lambert D. Prevalence of lower limb ulceration in an urban health district. Br J Surg. 1992;79(10):1032-1034.

11. Cornwall JV, Dore CJ, Lewis JD. Leg ulcers: epidemiology and aetiology. Br J Surg. 1986;73(9):693-696.

12. Abbade LP, Lastoria S. Venous ulcer: epidemiology, physiopathology, diagnosis and treatment. Int J Dermatol. 2005;44(6):449-456.

13. Greaves NS, Iqbal SA, Baguneid M, Bayat A. The role of skin substitutes in the management of chronic cutaneous wounds. Wound Repair Regen. 2013;21(2):194-210. doi: 10.1111/wrr.12029.

14. Moffatt CJ, Dorman MC. Recurrence of leg ulcers within a community ulcer service. J Wound Care. 1995;4(2):57-61.

15. Ruckley CV. Caring for patients with chronic leg ulcer. BMJ. 1998; 316(7129):407-408. 
16. Vowden KR, Vowden P. A survey of wound care provision within one English health care district. J Tissue Viability. 2009;18(1):2-6. doi: 10.1016/j.jtv.2008.11.003.

17. Vowden KR, Vowden P. The prevalence, management and outcome for patients with lower limb ulceration identified in a wound care survey within one English health care district. J Tissue Viability. 2009;18(1):13-19. doi: 10.1016/j.jtv.2008.11.002.

18. Ragnarson Tennvall G, Hjelmgren J. Annual costs of treatment for venous leg ulcers in Sweden and the United Kingdom. Wound Repair Regen. 2005;13(1):13-18.

19. Augustin M, Brocatti LK, Rustenbach SJ, Schafer I, Herberger K. Costof-illness of leg ulcers in the community. Int Wound J. 2014;11(3):283292. doi: 10.1111/j.1742-481X.2012.01089.x.

20. Clark RAF. Overview and general considerations of wound repair. In: Clark RAF, editor. Molecular and Cellular Biology of Wound Repair. 2nd ed. New York, NY: Plenum Press; 1996:3.

21. Eming SA, Krieg T, Davidson JM. Inflammation in wound repair: molecular and cellular mechanisms. J Invest Dermatol. 2007;127(3): 514-525.

22. Yamada KM, Clark RAF. Provisional matrix. In: Clark RAF, editor. Molecular and Cellular Biology of Wound Repair. 2nd ed. New York, NY: Plenum Press; 1996:51.

23. Eming SA, Koch M, Krieger A, et al. Differential proteomic analysis distinguishes tissue repair biomarker signatures in wound exudates obtained from normal healing and chronic wounds. J Proteome Res. 2010;9(9):4758-4766. doi: 10.1021/pr100456d.

24. Bucalo B, Eaglstein WH, Falanga V. Inhibition of cell proliferation by chronic wound fluid. Wound Repair Regen. 1993;1(3):181-186.

25. De Mattei M, Ongaro A, Magaldi S, et al. Time- and dose-dependent effects of chronic wound fluid on human adult dermal fibroblasts. Dermatol Surg. 2008;34(3):347-356. doi: 10.1111/j.1524-4725.2007.34068.x.

26. Phillips TJ, al-Amoudi HO, Leverkus M, Park HY. Effect of chronic wound fluid on fibroblasts. J Wound Care. 1998;7(10):527-532.

27. Raffetto JD, Vasquez R, Goodwin DG, Menzoian JO. Mitogen-activated protein kinase pathway regulates cell proliferation in venous ulcer fibroblasts. Vasc Endovascular Surg. 2006;40(1):59-66.

28. Seah CC, Phillips TJ, Howard CE, et al. Chronic wound fluid suppresses proliferation of dermal fibroblasts through a ras-mediated signaling pathway. J Invest Dermatol. 2005;124(2):466-474.

29. Katz MH, Alvarez AF, Kirsner RS, Eaglstein WH, Falanga V. Human wound fluid from acute wounds stimulates fibroblast and endothelial cell growth. J Am Acad Dermatol. 1991;25(6 Pt 1):1054-1058.

30. Renner R, Simon JC, Treudler R. Contact sensitization to modern wound dressings in 70 patients with chronic leg ulcers. Dermatitis. 2013;24(2):60-63. doi: 10.1097/DER.0b013e318284d9f2.

31. Estlander T, Keskinen H, Jolanki R, Kanerva L. Occupational dermatitis from exposure to polyurethane chemicals. Contact Dermatitis. 1992;27(3):161-165.

32. Turan H, Saricaoglu H, Turan A, Tunali S. Polyurethane toilet seat contact dermatitis. Pediatr Dermatol. 2011;28(6):731-732. doi: 10.1111/j.1525-1470.2011.01482.x.

33. Mughal AA, Hughes TM, Stone NM. Allergic contact dermatitis to lyofoam polyurethane dressing used as padding by a patient with above-knee amputation. Dermatitis. 2014;25(1):44-45. doi: 10.1097/ DER.0b013e3182a5d852.

34. Machet L, Couhe C, Perrinaud A, Hoarau C, Lorette G, Vaillant L. A high prevalence of sensitization still persists in leg ulcer patients: a retrospective series of 106 patients tested between 2001 and 2002 and a meta-analysis of 1975-2003 data. Br J Dermatol. 2004;150(5):929-935. doi: 10.1111/j.1365-2133.2004.05917.x.

35. Gallenkemper G, Rabe E, Bauer R. Contact sensitization in chronic venous insufficiency: modern wound dressings. Contact Dermatitis. 1998;38(5):274-278.

36. Vig S, Dowsett C, Berg L, et al. Evidence-based recommendations for the use of negative pressure wound therapy in chronic wounds: steps towards an international consensus. JTissue Viability. 2011;(20 Suppl 1): S1-S18. doi: 10.1016/j.jtv.2011.07.002.
37. Suess JJ, Kim PJ, Steinberg JS. Negative pressure wound therapy: evidence-based treatment for complex diabetic foot wounds. Curr Diab Rep. 2006;6(6):446-450.

38. Matsumura H, Imai R, Ahmatjan N, et al. Removal of adhesive wound dressing and its effects on the stratum corneum of the skin: comparison of eight different adhesive wound dressings. Int Wound J. 2014;11(1):50-54. doi: 10.1111/j.1742-481X.2012.01061.x.

39. Tuner TD. Hospital usage of absorbent dressings. Pharmaceutical J. 1979;222:421-426.

40. Thomas S, Young S. Exudate-handling mechanisms of two foam-film dressings. J Wound Care. 2008;17(7):309-315.

41. Thomas S. Laboratory findings on the exudate-handling capabilities of cavity foam and foam-film dressings. J Wound Care. 2010;19(5):192, 194-199. doi: 10.12968/jowc.2010.19.5.48049.

42. O’Meara S, Al-Kurdi D, Ologun Y, Ovington LG, Martyn-St James M, Richardson R. Antibiotics and antiseptics for venous leg ulcers. Cochrane Database Syst Rev. 2014;1:CD003557. doi: 10.1002/14651858.CD003557.

43. Weiss RA, Weiss MA, Ford RW. Randomized comparative study of cutinova foam and allevyn with jobst UlcerCare stockings from the treatment of venous stasis ulcers. Phlebology. 1996;11(Suppl 1): S14-S16.

44. Andersen KE, Franken CPM, Gad P, et al. A randomized, controlled study to compare the effectiveness of two foam dressings in the management of lower leg ulcers. Ostomy Wound Manage. 2002;48(8): 34-41.

45. Franks PJ, Moody M, Moffatt CJ, et al. Randomized trial of two foam dressings in the management of chronic venous ulceration. Wound Repair Regen. 2007;15(2):197-202.

46. Norkus A, Dargis V, Thomsen JK, et al. Use of a hydrocapillary dressing in the management of highly exuding ulcers: a comparative study. $J$ Wound Care. 2005;14(9):429-432.

47. Zuccarelli F. A comparative study of the hydrocellular dressing allevyn and the hydrocolloid dressing duoderm in the local treatment of leg ulcers. Phlebologie. 1992;45(4):529-533.

48. Bowszyc J, Bowszyc-Dmochowska M, Kazmierowski M, Ben-Amer HM, Garbowska T, Harding E. Comparison of two dressings in the treatment of venous leg ulcers. J Wound Care. 1995;4(3):106-110.

49. Thomas S, Banks V, Bale S, et al. A comparison of two dressings in the management of chronic wounds. J Wound Care. 1997;6(8):383-386.

50. Charles H, Callicot C, Mathurin D, Ballard K, Hart J. Randomised, comparative study of three primary dressings for the treatment of venous ulcers. Br J Community Nurs. 2002;7(Suppl 6):48-54.

51. Vanscheidt W, Sibbald RG, Eager CA. Comparing a foam composite to a hydrocellular foam dressing in the management of venous leg ulcers: a controlled clinical study. Ostomy Wound Manage. 2004;50(11):42-55.

52. Banerjee AK, Levy DW, Rawlinson DA. A comparative study of Synthaderm and conventional dressings. Care Elderly. 1990;2(3): $123-125$.

53. Andriessen A, Polignano R, Abel M. Monitoring the microcirculation to evaluate dressing performance in patients with venous leg ulcers. J Wound Care. 2009;18(4):145-150.

54. Callam MJ, Harper DR, Dale JJ, et al. Lothian and forth valley leg ulcer healing trial part 2: knitted viscose dressing versus a hydrocellular dressing in the treatment of chronic leg ulceration. Phlebology. 1992;7(4):142-145.

55. Reiber GE. The epidemiology of diabetic foot problems. Diabet Med. 1996;13(Suppl 1):S6-S11.

56. Singh N, Armstrong DG, Lipsky BA. Preventing foot ulcers in patients with diabetes. JAMA. 2005;293(2):217-228.

57. Abbott CA, Carrington AL, Ashe H, et al. The north-west diabetes foot care study: incidence of, and risk factors for, new diabetic foot ulceration in a community-based patient cohort. Diabet Med. 2002;19(5): 377-384.

58. Kumar S, Ashe HA, Parnell LN, et al. The prevalence of foot ulceration and its correlates in type 2 diabetic patients: a population-based study. Diabet Med. 1994;11(5):480-484. 
59. Dumville JC, Deshpande S, O'Meara S, Speak K. Foam dressings for healing diabetic foot ulcers. Cochrane Database Syst Rev. 2013;6:CD009111. doi: 10.1002/14651858.CD009111.pub3.

60. Blackman JD, Senseng D, Quinn L, Mazzone T. Clinical evaluation of a semipermeable polymeric membrane dressing for the treatment of chronic diabetic foot ulcers. Diabetes Care. 1994;17(4):322-325.

61. Mazzone T, Blackman J. Evaluation of a new loaded foam membrane on the healing rate of diabetic foot ulcers. 1st Joint Meeting of the Wound Healing Society and the European Tissue Repair Society; August 1993; Amsterdam, the Netherlands.

62. Roberts G, Hammad L, Haggan G, et al. Hydrocellular against nonadherent dressings to treat diabetic foot ulcers. A randomised controlled study. 11th ETRS Annual Conference. Wound Repair Regen. 2001; 9(5):402.

63. Clever HU, Dreyer M. Comparing two wound dressings for the treatment of neuropathic diabetic foot ulcers. In: Proceedings of the 5th European Conference on Advances in Wound Management. London, UK: MacMillan; 1996:201-203.

64. Baker NR, Creevy J. A randomised comparative pilot study to evaluate allevyn hydrocellular dressings and sorbsan calcium-alginate dressings in the treatment of diabetic foot ulcers. Presented at the 6th Annual Symposium on Advanced Wound Care; 1993; San Diego, CA.

65. Foster AVM, Greenhill MT, Edmonds ME. Comparing two dressings in the treatment of diabetic foot ulcers. J Wound Care. 1994;3:224-228.

66. Smith ME, Totten A, Hickam DH, et al. Pressure ulcer treatment strategies: a systematic comparative effectiveness review. Ann Intern Med. 2013;159(1):39-50. doi: 10.7326/0003-4819-159-1-201307020-00007.

67. Sebern MD. Pressure ulcer management in home health care: efficacy and cost effectiveness of moisture vapor permeable dressing. Arch Phys Med Rehabil. 1986;67(10):726-729. doi: 0003-9993(86)90004-3.

68. Bouza C, Saz Z, Munoz A, Amate JM. Efficacy of advanced dressings in the treatment of pressure ulcers: a systematic review. $J$ Wound Care. 2005;14(5):193-199.

69. Health Quality Ontario. Management of chronic pressure ulcers: an evidencebased analysis. Ont Health Technol Assess Ser. 2009;9(3): 1-203.

70. San Miguel L, Torra i Bou JE, Verdu Soriano J. Economics of pressure-ulcer care: review of the literature on modern versus traditional dressings. J Wound Care. 2007;16(1):5-9.

71. Royal College of Nursing (UK). The management of pressure ulcers in primary and secondary care, a clinical practice guideline. NICE Clinical Guidelines, No 29. London: Royal College of Nursing (UK); 2005.

72. Guillen-Sola M, Soler Mieras A, Tomas-Vidal AM; GAUPP-Expert Panel. A multi-center, randomized, clinical trial comparing adhesive polyurethane foam dressing and adhesive hydrocolloid dressing in patients with grade II pressure ulcers in primary care and nursing homes. BMC Fam Pract. 2013;14:196. doi: 10.1186/1471-2296-14-196.

73. Alexander S. Malignant fungating wounds: epidemiology, aetiology, presentation and assessment. J Wound Care. 2009;18(7):273-274, 276-278, 280.

74. Gibson S, Green J. Review of patients' experiences with fungating wounds and associated quality of life. $J$ Wound Care. 2013;22(5):265266, 268, 270-272, passim. doi: 10.12968/jowc.2013.22.5.265.

75. Lo SF, Hu WY, Hayter M, Chang SC, Hsu MY, Wu LY. Experiences of living with a malignant fungating wound: a qualitative study. J Clin Nurs. 2008;17(20):2699-2708. doi: 10.1111/j.1365-2702.2008.02482.x.
76. Probst S, Arber A, Faithfull S. Coping with an exulcerated breast carcinoma: an interpretative phenomenological study. JWound Care. 2013;22(7):352354, 356-358, 360. doi: 10.12968/jowc.2013.22.7.352.

77. Selby T. Managing exudate in malignant fungating wounds and solving problems for patients. Nurs Times. 2009;105(18):14-17.

78. Kalemikerakis J, Vardaki Z, Fouka G, et al. Comparison of foam dressings with silver versus foam dressings without silver in the care of malodorous malignant fungating wounds. J BUON. 2012;17(3):560-564.

79. White RJ, Cutting K, Kingsley A. Topical antimicrobials in the control of wound bioburden. Ostomy Wound Manage. 2006;52(8):26-58.

80. Aziz Z, Abu SF, Chong NJ. A systematic review of silver-containing dressings and topical silver agents (used with dressings) for burn wounds. Burns. 2012;38(3):307-318. doi: 10.1016/j.burns.2011.09.020.

81. Jorgensen B, Friis GJ, Gottrup F. Pain and quality of life for patients with venous leg ulcers: Proof of concept of the efficacy of biatain-ibu, a new pain reducing wound dressing. Wound Repair Regen. 2006;14(3): 233-239.

82. Steffansen B, Herping SP. Novel wound models for characterizing ibuprofen release from foam dressings. Int J Pharm. 2008;364(1):150-155. doi: 10.1016/j.ijpharm.2008.07.025.

83. Cigna E, Tarallo M, Bistoni G, et al. Evaluation of polyurethane dressing with ibuprofen in the management of split-thickness skin graft donor sites. In Vivo. 2009;23(6):983-986.

84. Markl P, Prantl L, Schreml S, Babilas P, Landthaler M, Schwarze H. Management of split-thickness donor sites with synthetic wound dressings: results of a comparative clinical study. Ann Plast Surg. 2010;65(5):490-496. doi: 10.1097/SAP.0b013e3181d37624.

85. Gottrup F, Jorgensen B, Karlsmark T, et al. Less pain with biatain-ibu: initial findings from a randomised, controlled, double-blind clinical investigation on painful venous leg ulcers. Int Wound J. 2007;4(Suppl 1): 24-34.

86. Gottrup F, Jorgensen B, Karlsmark T, et al. Reducing wound pain in venous leg ulcers with biatain ibu: a randomized, controlled double-blind clinical investigation on the performance and safety. Wound Repair Regen. 2008;16(5):615-625. doi: 10.1111/j.1524475X.2008.00412.x.

87. Palao i Domenech R, Romanelli M, Tsiftsis DD, et al. Effect of an ibuprofen-releasing foam dressing on wound pain: a real-life RCT. $J$ Wound Care. 2008;17(8):342, 344-348.

88. Arapoglou V, Katsenis K, Syrigos KN, et al. Analgesic efficacy of an ibuprofen-releasing foam dressing compared with local best practice for painful exuding wounds. JWound Care. 2011;20(7):319-320, 322-325. doi: 10.12968/jowc.2011.20.7.319

89. Fogh K, Andersen MB, Bischoff-Mikkelsen M, et al. Clinically relevant pain relief with an ibuprofen-releasing foam dressing: results from a randomized, controlled, double-blind clinical trial in exuding, painful venous leg ulcers. Wound Repair Regen. 2012;20(6):815-821. doi: 10.1111/j.1524-475X.2012.00844.X.

90. Jorgensen B, Gottrup F, Karlsmark T, Bech-Thomsen N, Sibbald RG. Combined use of an ibuprofen-releasing foam dressing and silver dressing on infected leg ulcers. $J$ Wound Care. 2008;17(5):210-214.

91. Schulz KF, Altman DG, Moher D; CONSORT Group. CONSORT 2010 statement: updated guidelines for reporting parallel group randomized trials. Ann Intern Med. 2010;152(11):726-732. doi: 10.7326/00034819-152-11-201006010-00232.
Chronic Wound Care Management and Research

\section{Publish your work in this journal}

Chronic Wound Care Management and Research is an international, peer reviewed, open access, online journal publishing original research, reviews, editorials, and commentaries on the causes and management of chronic wounds and the major issues related to chronic wound management. Topics also include chronic wounds as comorbidities to other

\section{Dovepress}

conditions, patient adherence to therapy, and the economic burden of chronic wounds. The manuscript management system is completely online and includes a very quick and fair peer review system, which is all easy to use. Visit http://www.dovepress.com/testimonials.php to read real quotes from published authors. 